\title{
Comparison of transurethral incision of the prostate and silodosin in patients having benign prostatic obstruction in terms of retrograde ejaculation
}

\author{
Basri Cakiroglu ${ }^{1}$, Aydin Ismet Hazar ${ }^{2}$, Orhun Sinanoglu ${ }^{3}$, Ersan Arda ${ }^{1}$, Sinan Ekici ${ }^{1}$ \\ ${ }^{1}$ Hisar Intercontinental Hospital, Department of Urology, Istanbul, Turkey; \\ ${ }^{2}$ Gaziosmanpaşa Taksim Eğitim Araştırma Hastanesi, Department of Urology Istanbul, Turkey; \\ ${ }^{3}$ Maltepe University, Medical School Department of Urology, Istanbul, Turkey.
}

\begin{abstract}
Summary Background: To compare the functional outcomes and retrograde ejaculation (RE) after transurethral incision of the prostate (TUIP) or silodosin in bladder outlet obstruction (BOO) secondary to a small prostate.

Methods: Prospectively collected data from December 2011 through December 2014 of 192 LUTS patients having fertility concerns with prostate volume smaller than $40 \mathrm{ml}$ receiving either TUIP or silodosin treatment were prospectively reviewed. The treatment outcomes were evaluated and compared. Results: TUIP was performed in 96 cases and silodosin $8 \mathrm{mg}$ was prescribed in 96 cases. At $12^{\text {th }}$ months after TUIP or continuous silodosin treatment, the decrease in mean International Prostate Symptom Score (IPSS) and postvoiding residual urine (PVR) and the improvement of mean maximal flow rate $\left(Q_{\max }\right)$ were significant $(p=0.000)$. The improvement in IPPS and Qmax was significantly higher in TUIP group compared to silodosin group $(p=0.005, p=0.000)$ with a lower rate of retrograde ejaculation (RE) in TUIP group. (11/96 vs 33/96) $(p=0.000)$

Conclusions: Both TUIP and silodosin ensures comparable improvement in PVR, IPSS and $\mathcal{Q}_{\max }$ with a lower rate of $R E$ on the TUIP group in prostates weighing less than 40 grams suggesting that TUIP is a better choice in younger patiens seeking preservation of ejaculation with fertility concerns.
\end{abstract}

KEY WORDS: Prostate; Retrograde ejaculation; Silodosin; Transurethral incision prostate.

Submitted 26 May 2016; Accepted 19 July 2016

\section{INTRODUCTION}

Lower urinary tract symptoms (LUTS) due to bladder outlet obstruction (BOO) are a common problem in aging males. Benign prostatic hyperplasia ( $\mathrm{BPH})$ is the most common cause of LUTS (1).

The treatment of symptomatic $\mathrm{BPH}$ is to relieve the $\mathrm{BOO}$ due to enlarged portion of the prostate. This can be ensured with surgery definitively or with medications providing symptomatic relief. However, the invasive treatment modalities are not free of complications, including permanent urinary incontinence, retrograde ejaculation (RE) as well as erectile dysfunction (ED) (2). Therefore, to avoid invasive methods, two main categories of drugs are used for the treatment of sympto- matic BPH; one blocks the $\alpha 1$-adrenoreceptors, the other inhibits the enzyme $5 \alpha$-reductase. The former category is expected to provide relatively rapid symptom relief starting within 2-6 weeks (3).

Silodosin, is an adrenergic blocker considered to be highly selective for $\alpha$ la receptor subtype and confirmed to be highly effective in patients with BPH. However, almost $70 \%$ of patients report either anejaculation or hypospermia, with a concomitant orgasmic function (OF) impairment in $17 \%$ of the patients. Younger patients claimed higher rates of ejaculatory dysfunction (4).

Transurethral resection of the prostate (TURP) is the gold standard for surgical treatment of BPH. Like many invasive modalities, this procedure is associated with with significant morbidity such as bleeding requiring blood transfusion (3\%), and hyponatremia (TUR syndrome, 1\%) as well as long-term complications such as stricture (7\%), surgical revision $(6 \%)$, significant urinary tract infection (4\%), bleeding incontinence (3\%), erectile dysfunction (10\%), and ejaculatory dysfunction $(65 \%)(5,6)$.

Furthermore, it may be an over-treatment for small size prostate in younger patients seeking protection of ejaculatory function. In this context, transurethral incision of the prostate (TUIP) became a an established treatment for BOO secondary to small-size BPH (7). TUIP has been reported to be an equivalent symptomatic improvement for men with prostate volume $<30 \mathrm{~mL}$, with the advantages of less hemorrhage and less sexual dysfunction such as ED or RE than TURP $(7,8)$.

In the present study, our objective is to compare the outcomes of TUIP and silodosin treatment in men with LUTS due to BPH seeking protection of fertility in terms of antegrade ejaculation.

\section{MATERIALS AND MEthods}

A review of prospectively collected data of patients having LUTS due to BPH with ejaculatory concerns receiving silodosin $8 \mathrm{mg}$ or undergoing TUIP. Inclusion criteria were patients with mild-moderate LUTS, seeking preservation of fertility, age $\leq 60$ years prostate volume $\leq 40 \mathrm{cc}$ and preoperative cystoscopic evaluation. All patients signed an informed consent agreeing to supply their own anonymous 
information for the study. Patients included in the alpha blocker treatment arm were prescribed to receive daily dosing silodosin $8 \mathrm{mg}$ for a 12 -months course. For TUIP procedure and silodosin treatment, prostate volume $>40 \mathrm{cc}$, the presence of middle lobe, a history of prostate surgery or history of concomitant urethral stricture and hypersensitivity to alpha blockers, orthostatic hypertension, other drug interaction were exclusion criteria, respectively. All TUIP procedures were performed or supervised by a single surgeon with a continuous flow $26 \mathrm{Ch}$ resectoscope and a video camera. The bladder neck was deeply incised at 5 and 7 o'clock positions just distal to each ureteral orifice to create a groove down to the true capsule to both side of the verumontanum. A 3-way 20Ch Foley catheter was inserted and connected to drainage and minimal saline irrigation. The patient was discharged once the urine was clear and the patient was able to void without a catheter. The follow-up visits were at 1,6 , and 12 months and then annually. Baseline and follow-up data were compared both subjectively and objectively in terms of the International Prostate Symptoms Score (IPSS), International Index of Erectile Function (IIEF), post-void residual urine volume (PVR) (mL), peak flow rate $\left(\mathrm{Q}_{\max }\right)$. Only baseline and post treatment $12^{\text {th }}$ month data were then collected and analyzed.

\section{Statistics}

The SPSS 16.0 (Statistical Package for Social Sciences, Chicago, USA) software was used for all statistical evaluations. Changes from baseline data for the same group were compared using the paired t-test while between groups comparison was done by the Fisher exact test for categorical variables and Mann Whitney-U test for continuous variables. P value of less than 0.05 was considered statistically significant.

\section{RESULTS}

Ninety six patients underwent TUIP and 96 patients received silodosin $8 \mathrm{mg}$. The differences in baseline parameters of treatment groups were not statistically significant; mean age, IPSS, prostate volume, IIEF, PVR, Qmax and PSA were $48.8 \pm 7.6$ vs $48.3 \pm 6.8,12.9 \pm 4.0$ vs $11.9 \pm 3.9$, $30.1 \pm 6.2$ vs $31.5 \pm 4.6,24.9 \pm 3.2$ vs $25 \pm 3.2$, $68.2 \pm 29.6$ vs $68.0 \pm 26.2,12 \pm 3.5$ vs $12 \pm 2.4$ and, $1.3 \pm 0.8$ vs $1.4 \pm 0.7$ in TUIP and silodosin groups, respectively (Table 1 ). Both groups were comparable in subjective and objective voiding parameters within follow up period at $3^{\text {th }}, 6^{\text {th }}$ and $9^{\text {th }}$ month. At $12^{\text {th }}$ months after TUIP and continuous silodosin $8 \mathrm{mg}$ treatment, the decrease in mean IPSS, and PVR and the improvement of mean maximal flow rate $\left(Q_{\text {max }}\right)$ were significant in both groups $(p=0.000)$. No significant change occured in IIEF scores of either groups. The improvement in IPSS and Qmax was significantly higher in TUIP group compared to silodosin group $(4.7 \pm 2.0$ vs $5.7 \pm 2.6$ and $20.8 \pm 23.2$ vs $26.5 \pm$
26.8) $(\mathrm{p}=0.005, \mathrm{p}=0.000)($ Table 2$)$ with a lower rate of RE in TUIP group (11/96 vs 33/96) ( $\mathrm{p}=0.000)$ (Table 3). IIEF scores in TUIP and silodosin groups at $12^{\text {th }}$ month were $24.9 \pm 3.1$ vs $25.3 \pm 3.2(\mathrm{p}=0.389)$.

\section{Discussion}

The management of $\mathrm{BOO}$ in $\mathrm{BPH}$ patients is divided into medical and surgical treatment modalities. Medical therapy for the common condition of BPH consists of alpha blockers and/or 5-alpha-reductase inhibitors, which can both lead to sexual dysfunction and declines in ejaculatory function (9).

According to clinical experience, the younger patients are more likely to encounter ejaculatory and orgasmic problems when using alpha blockers, so the physicians should be more careful when prescribing medicines.

Additionally, medical treatment options including alpha blokers for BPH are only for relieving or palliating symptoms of LUTS, on the other hand the surgery is the definitive method to eliminate $\mathrm{BOO}$ due to prostatic enlargement. Among surgical treatment modalities open prostatectomy and TURP are the leading entities. With the presence of gold standard TURP, the minimally invasive procedure, TUIP, in patients with small prostates has not gained enough popularity. In fact, the risk of blood transfusion and retrograde ejaculation are significantly lower with TUIP when compared to TURP. The reintervention rate is lower for TURP, but this is compensated with decreased morbidity of TUIP (10). TUIP is comparable to TURP in terms of functional outcomes within the first 12
Table 1.

Preoperative parameters of patients in treatment groups.

\begin{tabular}{lccccccc}
\hline & Age & IPSS & Volume & IIEF & PVR & $\mathbf{Q}_{\max }$ & PSA \\
\hline TUIP $(\# 96)$ & $48.8 \pm 7.6$ & $12.9 \pm 4.0$ & $30.1 \pm 6.2$ & $24.9 \pm 3.2$ & $68.2 \pm 29.6$ & $12 \pm 3.5$ & $1.3 \pm 0.8$ \\
\hline Silodosin $(\# 96)$ & $48.3 \pm 6.8$ & $11.9 \pm 3.9$ & $31.5 \pm 4.6$ & $25.0 \pm 3.2$ & $68.0 \pm 26.2$ & $12 \pm 2.4$ & $1.4 \pm 0.7$ \\
\hline P value & 0.66 & 0.97 & 0.07 & 0.74 & 0.96 & 0.98 & 0.44 \\
\hline $\begin{array}{l}\text { TUIP: Transurethral incision of the prostate, IPSS: International prostate symptom score, IIEF: International } \\
\text { index of erectile function, PVR: Post voiding residue, } \text { Q }_{\text {max }} \text { Maximum flow rate, PSA: Prostate specific antigen. } \\
\text { Student T test }\end{array}$ & & & & & & \\
\end{tabular}

Table 2.

Postperative parameters of patients in treatment groups.

\begin{tabular}{lcccc}
\hline & IPSS & IIEF & PVR & $\mathbf{Q}_{\max }$ \\
\hline TUIP $(\# 96)$ & $4.7 \pm 2.0$ & $24.9 \pm 3.1$ & $20.8 \pm 23.24$ & $19.6 \pm 3.9$ \\
\hline Silodosin (\#96) & $5.7 \pm 2.6$ & $25.3 \pm 3.2$ & $26.5 \pm 26.8$ & $15.0 \pm 4.7$ \\
\hline $\mathbf{P}$ value & 0.005 & 0.389 & 0.123 & 0.000 \\
\hline TUIP: Transurethral incision of the prostate, IPSS: International prostate symptom \\
score, IIEF: International index of erectile function, PVR: Post voiding residue, \\
$\mathbf{Q}_{\text {max }}$ Maximum flow rate. \\
Student T test
\end{tabular}

Table 3.

Retrograde ejaculation (RE) status according to treatment modality.

\begin{tabular}{|lccc|}
\hline \multicolumn{1}{c}{ RE (-) } & RE $(+)$ & \multicolumn{1}{c|}{ Total } \\
\hline TUIP & $85(88.5 \%)$ & $11(11.5 \%)$ & $96(100 \%)$ \\
\hline Silodosin & $63(65.6 \%)$ & $33(34.4 \%)$ & $96(100 \%)$ \\
\hline Total & $148(77.1 \%)$ & $44(22.9 \%)$ & $192(100 \%)$ \\
\hline $\begin{array}{l}\text { TUIP: Transurethral incision of the prostate, } p=0.000 . \\
\text { Chi square test }\end{array}$ \\
\hline
\end{tabular}


months postoperatively, except $\mathrm{Q}_{\max }$ that was more significantly improved with TURP (11).

The operative time and hospital stay is shorter in the TUIP procedure (12). In the present study, we compared silodosin with the invasive procedure, TUIP. Prostate volume $<40 \mathrm{cc}$ was the inclusion criteria in contrast to the majority of previous reports suggesting that prostate volume should be taken $<30 \mathrm{cc}$ in order to obtain successful results. However, there is little evidence on long-term effectiveness and there is no clear cutoff prostate size that achieves long-term favourable outcomes after TUIP (13). In our series, the improvement in IPSS, $\mathrm{Q}_{\max }$ and IIEF was significantly higher in TUIP group compared to silodosin group whereas RE rate was significantly lower in TUIP group compared to silodosin group. To our knowledge, this is the first study comparing RE status in terms of alpha bloker treatment and TUIP procedure. There are comparative reports only among different surgical methods in this regard. In the present study, RE rates in silodosin vs TUIP were $34.4 \%$ and $11.5 \%$, respectively. A systematic review comparing TURP and TUIP procedures reported that RE rates were $65.4 \%$ and $18.2 \%$ respectively (14). The major adverse events of silodosin are ejaculatory dysfunction, dizziness, diarrhea or loose stools, skin rash, nasal congestion, abnormal liver function and thrombocytopenia. Patients underwnt TUIP avoid all these adverse events additionally (15).

Lastly, in terms of TUIP complications in our series, there were not any short term complication such as bleeding and long term complication such as urethral stricture or bladder neck contracture. Of interest, reoperation after TUIP for the management of LUTS secondary to BPH was needed after 12 months in 1 patient. There were limitations to our study. First, it was prospective in nature, and second, only the 12 month follow up data after initial treatment were compared. Lack of urodynamic studies may be considered as another limitation.

\section{Conclusions}

Young patients with LUTS due to BPH using highly uroselective alpha blokers experience quite often anejaculation, aspermia and reduced orgasm feeling. Therefore, TUIP remains as an alternative, safe and efficient procedure to treat $\mathrm{BOO}$ secondary to a small-sized prostate in young BPH patients seeking preservation of ejaculatory and orgasmic function with both infertility and sexual dissatisfaction concerns.

\section{ACKNOWLEDGMENT}

All the authors below deny any meaningful affiliation or involvement, either direct or indirect, with any organization or entity with a direct financial interest in the subject matter or materials and any financial or material support for the work.

\section{RefERENCES}

1. Chute CG, Panser LA, Girman CJ, et al. The prevalence of prostatism: A population-based survey of urinary symptoms. J Urol. 1993; 150:85-9.
2. Reznicek SB. Common urologic problems in the elderly. Prostate cancer, outlet obstruction, and incontinence require special management. Postgrad Med. 2000; 107:1634.

3. Kaplan SA. Use of alpha-adrenergic inhibitors in treatment of benign prostatic hyperplasia and implications on sexual function. Urology. 2004; 63:428-34.

4. Serino A, Ventimiglia E, Boeri L, et al. Effects of silodosin on sexual function - realistic picture from the everyday clinical practice.Andrology. 2015; 3:1076-1081.

5. Reich O, Gratzke C, Bachmann A, et al. Morbidity, mortality and early outcome of transurethral resection of the prostate: a prospective multicenter evaluation of 10,654 patients. J Urol. 2008; 180:246-9.

6. Cakiroglu B, Sinanoglu O, Dogan AN. Safety of greenlight photoselective vaporisation of prostate in lower urinary tract symptoms due to benign prostatic hyperplasia in patients using anticoagulants due to cardiovascular comorbidities. Arch Ital Urol Androl. 2015; 87:141-3.

7. Lourenco T, Shaw M, Fraser C, et al. The clinical effectiveness of transurethral incision of the prostate: A systematic review of randomized controlled trials. World J Urol. 2010; 28:23-32.

8. Cakiroglu B, Gözüküçük R, Sinanoglu O. Efficacy and safety of $120 \mathrm{w}$ greenlight photoselective vaporisation of prostate in patients receiving anticoagulant drugs. J Pak Med Assoc. 2013; 63:1464-7.

9. Adam F, Stewart and Edward D. Kim Fertility Concerns for the Aging Male Urology. 2011; 78:496-499.

10. Taylor BL, Jaffe WI. Electrosurgical transurethral resection of the prostate and transurethral incision of the prostate (monopolar techniques). Can J Urol. 2015; 22 (Suppl 1):24-9.

11. Yang Q, Peters TJ, Donovan JL, et al. Transurethral incision compared with transurethral resection of theprostate for bladder outlet obstruction: A systematic review and meta-analysis of randomized controlled trials. J Urol. 2001; 165:1526-32.

12. Saporta L, Aridogan IA, Erlich N, Yachia D. Objective and subjective comparison of transurethral resection, transurethral incision and balloon dilatation of the prostate. A prospective study. Eur Urol. 1996; 29:439-45.

13. Hueber PA, Zorn KC. Let's not forget about TUIP: A highly underutilized, minimally-invasive and durable technique for men with $<$ g prostates. Can Urol Assoc J. 2015; 9:255-6.

14. Reich O, Gratzke C, Stief CG. Techniques and long term results of surgical procedures for BPH. Eur Urol. 2006; 4:970-78

15. Yamanishi T, Kaga K, Fuse M, et al. Six-year follow up of silodosin monotherapy for the treatment of lower urinary tract symptoms suggestive of benign prostatic hyperplasia: What are the factors for continuation or withdrawal? International J Urol. 2015; 22:1143-48.

\author{
Correspondence \\ Cakiroglu Basri, MD (Corresponding Author) \\ drbasri@gmail.com \\ Arda Ersan, MD \\ Ekici Sinan, $M D$ \\ Hisar Intercontinental Hospital, Department of Urology, \\ Saray Mh.Siteyolu Cad. No.7 34768 Umraniye, Istanbul, Turkey \\ Hazar Aydin Ismet, MD \\ Gaziosmanpaşa Taksim Eğitim Araştırma Hastanesi, \\ Department of Urology Istanbul, Turkey \\ Sinanoglu Orhun, $M D$ \\ Maltepe University, Medical School Department of Urology, \\ Istanbul, Turkey
}

